\title{
Ethanol-increased exhalation of mercury in mice
}

\author{
J. D. DUNN ${ }^{1}$, T. W. CLARKSON, AND L. MAGOS 2 \\ From the ${ }^{1}$ Department of Radiation Biology and Biophysics, School of Medicine and Dentistry, \\ University of Rochester, New York 14642, and the ${ }^{2}$ Toxicology Unit, Medical Research Laboratories, \\ Carshalton, Surrey, England
}

ABSTRACT CBA/J mice injected three days beforehand with ${ }^{203} \mathrm{HgCl}_{2}$ were given ethanol or water by gavage and placed in a chamber designed to collect exhaled mercury. Ethanol treatment led to an eightfold increase of counts accumulated on a filter over a four-hour period, compared with water-treated mice. The mercury-collection apparatus tested for extracorporeal contribution of volatilised mercury indicated that the counts originated from the air exhaled by the mice.

It has been shown that the excretion of mercury by laboratory animals via the urine and faeces does not total $100 \%$ of the body-burden loss (Rothstein and Hayes, 1960; Hayes and Rothstein, 1962; Rothstein and Hayes, 1964). Exhalation of small amounts of mercury detected in anaesthetised rats (Clarkson and Rothstein, 1964) and also in human volunteers (Hursh et al., 1976) indicate that this represents an excretory pathway, albeit a minor one, for the elimination of mercury. However, in the volunteer study in our laboratory, consumption of an alcoholic beverage 48 hours after a single low-level exposure to radiolabelled mercury vapour led to an increased rate of mercury exhalation in one particular volunteer. This unexpected rise in mercury elimination was investigated using mice exposed to mercuric chloride and ethanol as a model for the alcohol effect.

We report here that the rate of mercury exhalation in mice injected three days beforehand with ${ }^{203} \mathrm{HgCl}_{2}$ was dramatically increased, compared with control values, after administration of ethanol solutions.

\section{Materials and methods}

\section{APPARATUS}

Exhaled mercury was detected with a specially designed apparatus (Fig. 1). This comprised a polypropylene chamber modified from an ordinary one-litre reagent bottle (Sybron Corporation, Rochester, NY) rendered airtight with a No. 15 rubber stopper. Holes were drilled through the

Received for publication 2 September 1977 Accepted for publication 8 December 1977 stopper for an air intake and exhaust and a manometer probe. Several 50 cc disposable syringes (Pharmaseal Co., Glendale, CA) were modified by sawing off the needle seat, enlarging the remaining hole and reducing the overall length of the barrel to approximately $9 \mathrm{~cm}$. Each barrel housed one mouse; this was accomplished by inserting the plunger with the shaft sawn off and gently pushing the mouse through until the head was completely outside this 'capsule'. The diameter of the opening $(1.5 \mathrm{~cm})$ was too small to enable the mouse to wriggle out, but in each case the animal and apparatus were carefully examined to ensure unrestricted breathing as well as proper containment of the mouse. Five such capsules at a time were secured in the chamber in each experiment and, before the chamber was sealed with the stopper, distilled water was introduced inside the chamber to a predetermined mark below the opening of the capsules. This reduced the interior volume to approximately $200 \mathrm{cc}$ (with the stopper in place) and had the effect of having only the heads of the mice in the chamber. The entire sealed chamber was then placed in a water bath at $29^{\circ} \mathrm{C}$ to maintain a constant interior water temperature.

This temperature setting was arbitrary and based on the assumption that $29^{\circ} \mathrm{C}$ is well within the range of environmental temperatures in which the mice could maintain homoiothermy (Bernstein, 1966). Furthermore, as the mice were generally dry throughout the experiment, thermoregulation probably was not a greater problem for them than it would have been under non-experimental conditions with or without ethanol.

When the apparatus was operating, mercury-free 


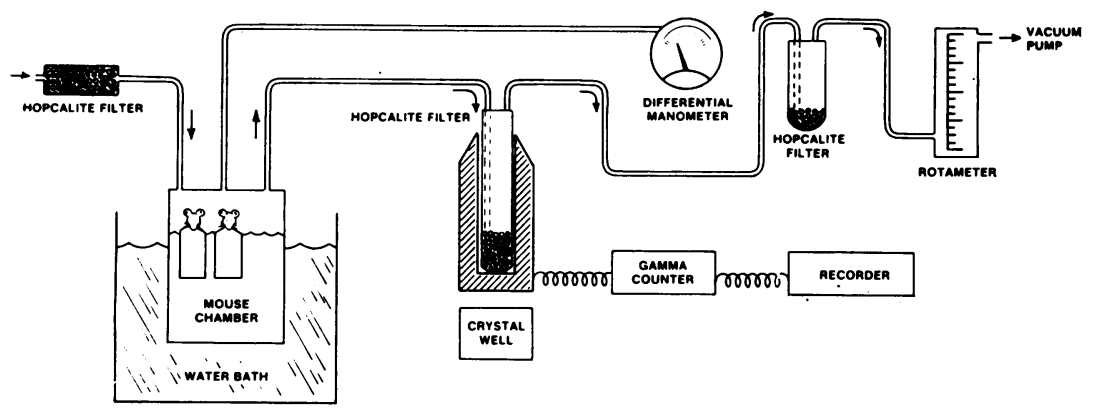

Fig. 1 The exhalation chamber and accessory apparatus, with arrows indicating direction of airflow. Only two mice are shown, for clarity.

air was drawn into the chamber head space and exhausted into an impinger containing Hopcalite (Mine Safety Appliances, Evans City, Pa). Hopcalite has been described as an effective adsorbant of mercury vapour (Clarkson and Rothstein, 1964). The Hopcalite impinger was placed in a sodium iodide crystal well counter (Magos et al., 1973), thus allowing continuous recordings of mercury accumulation. A flowmeter connected to a vacuum pump enabled air flow to be controlled precisely at a rate of one litre per minute and the slight negative pressure created in the chamber $\left(0.02\right.$ inches of $\left.\mathrm{H}_{2} \mathrm{O}\right)$ was monitored continuously with the manometer.

Before the experiment, this mercury collection system was checked for recoveries of known amounts of radioactive mercury vapour generated from ${ }^{203} \mathrm{HgCl}_{2}$ (Magos, 1968). The average recovery was $87 \cdot 4 \%(\mathrm{~N}=11)$.

\section{ANIMALS}

CBA/J female mice of approximately $25 \mathrm{gm}$ body weight were injected intraperitoneally on day zero with either $0.1 \mathrm{mg} / \mathrm{kg}$ (low mercury; $\mathrm{N}=10$ ) or 1.0 $\mathrm{mg} / \mathrm{kg}$ (high mercury; $\mathrm{N}=10$ ) of radiolabelled $\mathrm{HgCl}_{2}$ solutions prepared from ${ }^{203} \mathrm{HgCl}_{2}$ (New England Nuclear, Boston, Mass.), cold $\mathrm{HgCl}_{2}$ and saline. The low and high mercury injections had specific activities of $0.41 \mu \mathrm{Ci} / \mu \mathrm{gHg}$ and $0.06 \mu \mathrm{Ci} /$ $\mu \mathrm{gHg}$ respectively. Five mice in the high mercury group were randomly selected on day three to receive by intubation $5.5 \mathrm{gm} / \mathrm{kg}$ of a $25 \%(\mathrm{v} / \mathrm{v})$ ethanol solution prepared from $95 \%$ stock. Five mice in the low mercury group received the same dose of $12 \%$ (v/v) ethanol. The remaining animals in each group were given distilled water. Immediately after they had been dosed with ethanol or water, the mice were placed in the exhalation chamber for at least four hours. Some groups of mice were killed in the chamber by ether introduced through the air intake hose.

\section{Results}

Figure 2 shows the accumulation of radioactivity in the impinger when various groups were assayed. Mice in the high and low mercury groups given ethanol exhaled 8.25 and 8.67 times their control values respectively. That the mercury does not come from extracorporeal sources is indicated by the lack of increase in counts following ether administration.

The possibility of mercury volatilisation from excreta within the individual capsules was checked. Five mice were given high doses of mercury and treated with ethanol as previously described. After the mice had stayed in the chamber for six hours

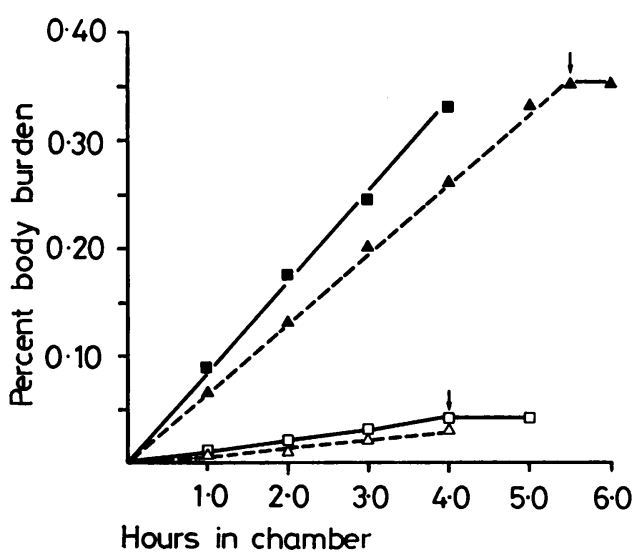

Fig. 2 Accumulation of radioactivity in the Hopcalite filter, plotted as a function of time for different treatment groups $(N=5)$. $\square 1.0 \mathrm{mg} / \mathrm{kg}$ mercury and $5.5 \mathrm{gm} / \mathrm{kg} 25 \%$ ethanol; $\Delta ; 0.1 \mathrm{mg} / \mathrm{kg}$ mercury and 5.5 $\mathrm{gm} / \mathrm{kg} 12 \%$ ethanol; $\square ; 1.0 \mathrm{mg} / \mathrm{kg}$ mercury and $0.25 \mathrm{ml}$ $\mathrm{H}_{2} \mathrm{O} ; \triangle ; 0 \cdot 1 \mathrm{mg} / \mathrm{kg}$ mercury and $0.25 \mathrm{ml} \mathrm{H}_{2} \mathrm{O}$. Arrows indicate time when ether was introduced into the chamber through the air intake hose. 


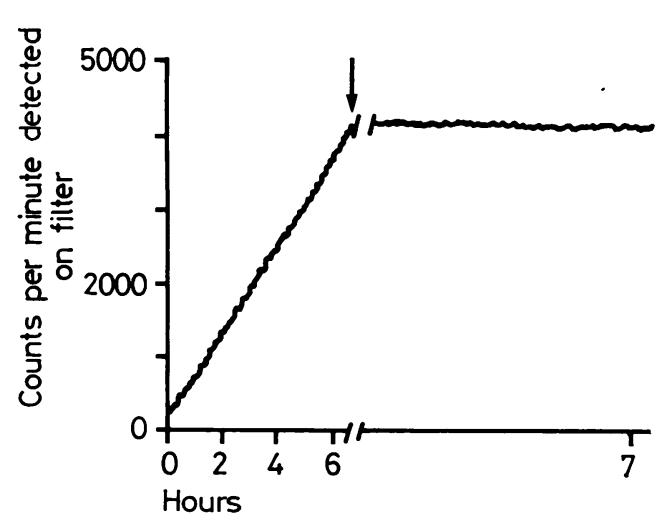

Fig. 3 Mercury accumulation from the apparatus with and without mice. The arrow at six hours indicates the point when the airflow was stopped and the mice were removed from the capsules. These capsules containing excreta were then replaced in the apparatus and the airflow resumed for approximately one hour (shown on expanded time-scale).

they were removed, and the capsules containing accumulated excreta were replaced in the apparatus. The result is shown in Figure 3.

\section{Discussion}

Mercury accumulation stops when the mice in the chamber have been given ether (Fig. 2). If significant amounts of mercury were being volatilised from the excreta, continued accumulation of mercury might be expected following the death of these animals. This was not observed even one hour later. In addition, when the mice were removed and the apparatus was run with the capsules containing only excreta, there was no further increase in filter counts (Fig. 3). This strongly suggests that there is little, if any, volatilisation from excreta under these conditions, and that the filtered radioactivity reflects pulmonary elimination of mercury. This conclusion is supported by reports of mercury in air sampled via endotracheal tube from treated rats (Clarkson and Rothstein, 1964) and from exposed volunteers exhaling into a collection device (Hursh et al., 1976). Although saliva and/or buccopharyngeal tissue cannot be ignored as a possible contributory source of volatile mercury in our experiments, the reports cited imply that the lungs have a major role.

Although the interaction of ethanol in the oxidation of mercury vapour has been the focal point of investigations in both humans and animals (NielsenKudsk, 1965; Nielsen-Kudsk, 1973; Leach et al., 1975), the effects seen here with mice given ionised mercury followed by treatment with ethanol have not been reported previously. Moreover, we have observed increased exhalation of mercury after the treated mice have been given a dose of ethanol as low as $0.1 \mathrm{gm} / \mathrm{kg}$ and the mechanism responsible for this phenomenon is under investigation. It may be that the reduction of ionic mercury to elemental mercury $\left(\mathrm{Hg}^{\circ}\right)$ takes place continuously but, in the absence of an inhibitor, most of the reduced mercury is re-oxidised before it can be exhaled. Furthermore, the role of ethanol may not be restricted to inhibiting re-oxidation; the metabolism of ethanol may also change the redox state of some cells (Lieber, 1973) leading to the conversion of intracellular mercury to a diffusible form which is transported in the blood to the alveolar space. It is also possible that, as well as one or more of these mechanisms, ethanol may prevent the trapping of reduced mercury in membranes. In all these hypotheses it has been assumed that mercury is exhaled in the elemental form, although some kind of volatile organic compound cannot be excluded as Hopcalite traps mercury irrespective of the chemical type.

Apart from the theoretical interest, the observed phenomenon may have a practical significance. At present there is no reliable index of the body burden of inorganic mercury. Measurement of exhaled mercury after a standard oral dose of ethanol might facilitate this assessment.

This study was supported by NIH Institutional Training Grant GM-07141, the Medical Research Council Toxicology Unit, Carshalton, Surrey and under contract with the US Department of Energy at the University of Rochester Department of Radiation Biology and Biophysics; it has been assigned Report No. UR-3490-1176.

\section{References}

Bernstein, E. S. (1966). Physiological characteristics. In Biology of the Laboratory Mouse, p. 343. Edited by E. Green. McGraw-Hill: New York.

Clarkson, T. W., and Rothstein, A. (1964). The excretion of volatile mercury by rats injected with mercuric salts. Health Physics, 10, 1115-1121.

Hayes, A., and Rothstein, A. (1962). The metabolism of inhaled mercury vapor in the rat studied by isotope techniques. Journal of Pharmacology and Experimental Therapeutics, 138, 1-10.

Hursh, J. B., Clarkson, T. W., Cherian, M. G., Vostal, J. J., and Vander Mallie, R. (1976). Clearance of mercury $(\mathrm{Hg}-$ 197, $\mathrm{Hg}-203)$ vapor inhaled by human subjects. Archives of Environmental Health, 31, 302-309.

Leach, L. J., Garman, R. H., Dunn, J. D., and DiGennaro, R. S. (1975). New toxicity information on mercury vapor and cinnabar dust. No. 17 Program and Abstracts. Twentyfirst Annual Conference on Bioassay, Environmental and Analytical Chemistry, San Francisco, California, USA. 
Lieber, C. S. (1973). Hepatic and metabolic effects of alcohol (1966-1973). Gastroenterology, 65, 821-846.

Magos, L. (1968). Uptake of mercury by the brain. British Journal of Industrial Medicine, 25, 315-318.

Magos, L., Clarkson, T. W., and Greenwood, M. R. (1973). The depression of pulmonary retention of mercury vapor by ethanol: identification of the site of action. Toxicology and Applied Pharmacology, 26, 180-183.

Nielsen-Kudsk, F. (1965). The influence of ethyl alcohol on the absorption of mercury vapour from the lungs in man. Acta Pharmacologica et Toxicologica, 23, 263-274.
Nielsen-Kudsk, F. (1973). Biological oxidation of elemental mercury. In Mercury, Mercurials and Mercaptans, p. 355. Edited by M. Miller and T. W. Clarkson. C. C. Thomas: Springfield, Illinois, USA.

Rothstein A., and Hayes, A. (1960). The metabolism of mercury in the rat studied by isotope techniques. Journal of Pharmacology and Experimental Therapeutics, 130, 166176.

Rothstein, A., and Hayes, A. (1964). The turnover of mercury in rats exposed repeatedly to inhalation of vapor. Health Physics, 10, 1099-1113. 